\title{
Desenvolvimento regional e lei PRODEMI: impactos sobre a geração de empregos e a receita pública em Itatiaia (RJ)
}

\author{
Rogério Gil Gonzaga' ${ }^{\prime}$ : Mariana do Amaral Antunes \\ gonzagapiau@yahoo.com.br
}

1. Universidade Federal Fluminense, Rua Desembargador Ellis Hermydio Figueira, 783, Volta Redonda, Brasil.

Histórico do Artigo:

Recebido em: 30 de maio de 2017

Aceito: 25 de setembro de 2017

Publicado: 5 de janeiro de 2018

Resumo: A falta de planejamento e de projetos dos agentes públicos geram vários impactos no desenvolvimento da economia local dos municípios. Sendo assim, projetos que incentivam investimentos devem ser elaborados no intuito de diminuir estes impactos, contribuindo para a geração de trabalho e renda. Entretanto, os incentivos à instalação de empresas devem conter regras claras para que suas instalações possam beneficiar diretamente a população local. Neste contexto, a presente pesquisa tem por objetivo analisar os impactos sobre a geração de empregos e a receita pública no município de Itatiaia (RJ) a partir da aprovação da Lei Complementar Nº 18 de 10 de junho de 2009, que institui e regulamenta o Programa de Desenvolvimento Econômico do Município de Itatiaia (PRODEMI).

Palavras-chave: Gestão Publica, Desenvolvimento Local, Capacitação Profissional, Lei PRODEMI.

\section{Regional development and PRODEMI law: impacts on the generation of employment and public revenue in Itatiaia (RJ)}

Abstract: The lack of planning and projects of the public agents generate several impacts in the development of the local economy of the municipalities. Therefore, projects that encourage investments must be designed in order to reduce these impacts, contributing to the generation of work and income. Incentives to set up businesses, however, must contain clear rules so that their facilities can directly benefit the local population. In this context, the present research aims to analyze the impacts on job creation and public revenue in the municipality of Itatiaia (RJ), in Brazil, as of the approval of Complementary Law No. 18 of June 10, 2009, which establishes and regulates the Program of Economic Development of the Municipality of Itatiaia (PRODEMI).

Keywords: Public administration, Regional development, Professional training, Lei PRODEMI.

\section{Desarrollo regional y ley PRODEMI: impactos sobre la generación de empleos y la receta pública en Itatiaia $(\mathrm{RJ})$}

Resumen: La falta de planificación y de proyectos de los agentes públicos generan varios impactos en el desarrollo de la economía local de los municipios. Siendo así, proyectos que incentivan inversiones deben ser elaborados con el fin de disminuir estos impactos, contribuyendo para la generación de trabajo y renta. Sin embargo, los incentivos a la instalación de empresas deben contener reglas claras para que sus instalaciones puedan beneficiar directamente a la población local. En este contexto, la presente investigación tiene por objetivo analizar los impactos sobre la generación de empleos y los ingresos públicos en el municipio de Itatiaia (RJ), en Brasil, a partir de la aprobación de la Ley Complementaria $\mathrm{N}^{\mathrm{0}} 18$ de 10 de junio de 2009, que instituye y reglamenta el Programa de Desarrollo Económico del Municipio de Itatiaia (PRODEMI).

Palabras clave:Técnicas compensatorias, Inundaciones urbanas, Control de la escorrentía superficial. 
Desenvolvimento regional e lei PRODEMI: impactos sobre a geração de empregos e a receita pública em Itatiaia (RJ)

\section{INTRODUÇÃO}

De acordo com o site do IBGE (2016), a origem do município de Itatiaia, localizado no estado do Rio de Janeiro, encontra-se ligada à de Resende, cidade ao qual pertencia até recentemente como sede distrital. Com a construção da Rodovia Presidente Dutra, por volta de 1950, Itatiaia iniciou um novo ciclo de atividades e desenvolvimento, com a instalação de indústrias de grande expressão e o início da atividade turística.

Por ter uma localização privilegiada, ao se situar entre os dois maiores polos econômicos do Brasil - a $115 \mathrm{~km}$ do Rio de Janeiro e $250 \mathrm{~km}$ de São Paulo -, a cidade estrategicamente contribui com a logística das empresas, diminuindo os custos devido aos modais de transportes de cargas.

No entanto, para que novas empresas continuassem se instalando na cidade, salientase o papel que exerce o gestor público, já que suas ações podem contribuir efetivamente para atrair novas empresas e gerar empregos e, com isso, contribuir com o aumento da renda local, além de diminuir o índice de desemprego.

Nesse contexto, foi estabelecido, em 2009, o Decreto 1810 do município de Itatiaia visando estimular o surgimento de um polo industrial na região, intenção confirmada com a Lei Complementar $n^{0} 18$ de 10 de junho de 2009, conhecida como Lei PRODEMI. Com a lei, esperava-se fomentar o desenvolvimento econômico e social através de concessão de incentivos fiscais a empresas que investissem e gerassem novos postos de trabalho. Com estes incentivos, foram instaladas na cidade mais de 25 empresas, sendo de pequeno, médio e grande porte, sobressaindo os setores automobilísticos, logística entre outros, contudo, muitas não empregaram a mão de obra local, fato que comumente é observado entre a população.

Neste sentido, é possível afirmar que o programa de desenvolvimento garantiu um desenvolvimento econômico sustentável, que beneficiou os moradores locais com a geração de emprego?

Diante da questão, o objetivo geral deste estudo é analisar os impactos gerados pelas indústrias, fábricas e comércios instalados na cidade de Itatiaia a partir da aprovação da Lei Complementar $\mathrm{n}^{0}$ 18, de 10 de junho de 2009, que institui e regulamenta o Programa de Desenvolvimento Econômico do Município de Itatiaia - PRODEMI. 
Para tanto, foi realizado um levantamento no âmbito da Secretaria de Desenvolvimento Econômico e Secretaria de Emprego e Geração de Renda visando verificar se o programa consegue garantir um desenvolvimento econômico sustentável que beneficie os moradores locais com a geração de emprego e renda na cidade de Itatiaia (RJ).

Assim, esperava-se analisar junto aos grupos empresariais os motivos da escolha da cidade de Itatiaia (RJ) para instalação de suas empresas; verificar se as vagas de emprego geradas pelos novos empreendimentos beneficiaram preferencialmente a mão de obra local; examinar quais os principais impactos gerados na economia local; e verificar ainda os motivos pela qual a mão de obra local não é empregada. Além disso, tal levantamento buscou apresentar as possibilidades de ações que convergem para a transformação da realidade da mão de obra qualificada; bem como identificar os principais impactos e problemas na relação entre a Lei PRODEMI e a indústria e o comércio do município de Itatiaia (RJ).

0 objetivo foi analisar os impactos gerados pós-aprovação dessa lei, tendo em vista as novas empresas instaladas na cidade, além de esclarecer a importância de políticas públicas eficazes que venham a contribuir para o desenvolvimento econômico e a sustentabilidade da economia local.

Nesse viés, acredita-se na possibilidade de apresentar ações que convergem para qualificação profissional, além de verificar se fomentou na população a necessidade de um currículo mais qualificado.

\section{MATERIAL E MÉTODOS}

Os problemas regionais podem contribuir para estagnar o desenvolvimento local; contudo, é importante salientar como os gestores públicos encaram estes problemas e simultaneamente se preparam para estes desafios. Esta é uma realidade de muitos municípios que sofrem em consequência das mudanças ocorridas na Constituição Federal de 1988. "Assim, o contexto da inclusão e da descentralização do planejamento como alternativas prioritárias para a gestão municipal são de grande valia” (SCHERER, 1987, apud CARVALHO, 2007, p. 4).

Por outro lado, a partir da Constituição Federal de 1988, ficou atribuída a autonomia dos municípios no que tange ao âmbito político, administrativo e financeiro, conforme 
Desenvolvimento regional e lei PRODEMI: impactos sobre a geração de empregos e a receita pública em Itatiaia $(\mathrm{RJ})$

estabelecido nos artigos 18, 29 e 30 (BRASIL, 1988). Tal autonomia passa a possibilitar, então, que os municípios possam participar de forma mais ativa no planejamento e desenvolvimento local, sobretudo por meio da elaboração de leis municipais, de competência de ordem exclusiva e suplementar (HELCIAS, 2015). Helcias (2015), citando Ferrari (2005), reforça que:

A Constituição Federal de 1988 trouxe como uma grande conquista a capacidade dos entes municipais de elaborarem suas próprias leis, as quais vieram estabelecer a vida dos Municípios, devendo estes observarem os limites estão previstos na Constituição Federal e Estadual (HELCIAS, 2015, apud FERRARI, 2005, p.6).

A partir da década de 1970, o desenvolvimento regional através das políticas publica no Brasil que se ancoravam através de ações estatais chegam aos limites (DINIZ E CROCCO, 2006; AMARAL FILH0, 2001, apud FERREIRA, LEOP0LDI e AMARAL, 2012). Segundo Lima e Simões (2009), o aumento de juros, a crise econômica, dificuldades de financiamento, além da inflação, endividamento e a crise fiscal foram primordiais para esses limites, gerando assim uma mudança no olhar para os problemas regionais. Para Ferreira (2012),

Os problemas regionais, antes analisados em escala nacional, passaram a ser discutidos em escala local, com menor intervenção federal, privilegiando políticas que procurassem desenvolver potencialidades locais sem necessariamente integrar 0 território nacional. (LIMA e SIMÕES, 2009, apud FERREIRA, 2012, p. 35).

Para Barquero (2002), estes fatos são importantes para uma nova forma de encarar os problemas locais, gerando novas estratégicas para o desenvolvimento, aumento de emprego, geração de renda e o nível de vida da população local. Segundo o autor, agora os principais agentes não se concentram mais na administração central do estado e sim nos administradores públicos e empresários locais, em um contexto no qual atores locais assumem papeis primordiais no planejamento e desenvolvimento dos municípios.

Para 0 estudo proposto, foi realizada uma breve pesquisa qualitativa na qual se pretendeu verificar a não empregabilidade da mão de obra local da cidade de Itatiaia (RJ) e os impactos gerados pelas empresas instaladas após a Lei Complementar $n^{0} 18$, de 10 de junho de 2009, conhecida como Lei PRODEMI, de âmbito municipal. Segundo Gerhardt e Silveira (2009, p.35), este tipo de pesquisa objetiva gerar conhecimentos para aplicação prática, dirigidos à solução de problemas específicos. Goldenberg (1997) complementa que: 
A pesquisa qualitativa não se preocupa com representatividade numérica, mas, sim, com o aprofundamento da compreensão de um grupo social, de uma organização, etc [...] uma vez que o pesquisador não pode fazer julgamentos nem permitir que seus preconceitos e crenças contaminem a pesquisa. (GOLDENBERG, 1997, p. 34).

Foram realizadas inicialmente pesquisas bibliográficas, incluindo os tópicos previstos na legislação e, na sequência, buscaram-se dados junto às Secretarias do município de Itatiaia, no Rio de Janeiro. Na secretaria de Emprego e Geração de Renda (SEGR), foi realizada uma entrevista com o Subsecretário local e na secretaria Fazenda e Desenvolvimento Econômico (SFDE), os dados foram obtidos juntos aos funcionários. Tal delimitação foi feita com base no que determina o art.15, parágrafo $1^{\circ}$ da Lei PRODEMI:

[...] a comissão que trata o caput deste artigo será constituída pelos titulares dos seguintes órgãos:

I - Secretaria Municipal de Desenvolvimento Econômico;

II - Secretaria Municipal de Fazenda [...] (ITATIAIA, 2009, p.6).

\section{RESULTADOS E DISCUSSÃ0}

A Lei Complementar $\mathrm{n}^{0} 18$ de 10 de junho de 2009, regulamenta o Programa de Desenvolvimento Econômico do Município de Itatiaia, o PRODEMI, que estabelece a concessão de incentivos fiscais a empresas interessadas em se instalar na cidade ou que pretendem expandir suas atividades, visando fomentar o desenvolvimento econômico e social local (ITATIAIA, 2009). De acordo com a lei, o art. $3^{\circ}$, parágrafo único determina que: “as vagas de emprego geradas pelos novos empreendimentos beneficiados deverão ser preferencialmente preenchidas por mão de obra local" (ITATIAIA, 2009, p.2).

Diante dessa premissa, na primeira entrevista, realizada com o Subsecretário de Emprego e Geração de Renda local, o objetivo foi levantar dados que contribuíssem no intuito de responder se as vagas de emprego geradas pelas empresas instaladas em Itatiaia a partir da vigência da Lei PRODEMI beneficiaram, de fato, os moradores locais, bem como os motivos da não empregabilidade da mão de obra local:

Antes os moradores tinham que buscar o CINE em Resende para se cadastrarem no banco de oferta de empregos. Contudo, após a criação da SEGR, ficou mais fácil para os moradores locais e até passamos a cadastrar moradores de outros municípios vizinhos. Neste sentido, os moradores locais buscam a secretaria e nós fazemos os 
Desenvolvimento regional e lei PRODEMI: impactos sobre a geração de empregos e a receita pública em Itatiaia $(\mathrm{RJ})$

cadastros, e quando as empresas solicitam candidatos direcionamos de acordo com perfil desejado da respectiva empresa. Atualmente, temos realizado cerca de 20 cadastros mensais e, até 0 momento, temos um total de 350 cadastros realizados neste ano (2016). Entretanto, o que se observa é que falta qualificação para nossos moradores, dificultando suas admissões. Outra dificuldade é que não temos o feedback das empresas com relação à contratação desses indicados. (Trecho entrevista SSEGR, 2016).

Diante da não comprovação dos dados sobre o quantitativo de empregados de Itatiaia no banco de dados da SEGR e das empresas locais, foi necessária uma consulta no Cadastro Geral de Empregados e Desempregados (CAGED) ${ }^{1}$.

A Lei PRODEMI determina o direito aos benefícios tributários e fiscais para as empresas incluídas no programa com base em três níveis de criação de novos postos de trabalho, sendo eles estabelecidos no art. $3^{0}$ :

\section{I - [...] gerar, no mínimo, 50 (cinquenta) novos empregos; \\ II - [...] gerar, no mínimo, 100 (cem) novos empregos; \\ III - [...] gerar, no mínimo, 200 (duzentos) novos empregos (ITATIAIA, 2009, p.2).}

A análise do CAGED constatou a geração de 520 empregos no período de agosto de 2011 a agosto de 2016, conforme demonstra a tabela abaixo:

Tabela 1. Cadastro Geral de Empregados e Desempregados (CAGED) em Itatiaia, no período de agosto de 2011 a agosto de 2016

\begin{tabular}{|c|c|}
\hline \multicolumn{2}{|l|}{ ITATIAIA } \\
\hline \multicolumn{2}{|l|}{ Admissões } \\
\hline Total & 10.892 \\
\hline \multicolumn{2}{|l|}{ Desligamentos } \\
\hline |Total & 10.372 \\
\hline \multicolumn{2}{|l|}{ Indicadores } \\
\hline Estoque Base para Recuperação: 01/01/2016 & 6.725 \\
\hline Estoque Recuperado Início do Período (01/08/2011) & 6.142 \\
\hline Estoque Recuperado Final do Período (31/08/2016) & 6.662 \\
\hline Variaçäo Emprego Absoluta de 01/08/2011 a 31/08/2016 & 520 \\
\hline
\end{tabular}

Fonte: MTE (2016).

\footnotetext{
${ }^{1} 0$ CAGED constitui importante fonte de informação do mercado de trabalho de âmbito nacional e de periodicidade mensal. foi criado pela Lei 4.923 de 23/12/1965, quando instituiu-se a obrigatoriedade das informações sobre admissões, desligamentos e transferências.
} 
Já na entrevista realizada junto a Secretaria de Fazenda e Desenvolvimento Econômico (SFDE), o objetivo era levantar dados para analisar os impactos gerados na economia e as ações que convergem para transformação de uma mão de obra mais qualificada, bem como os principais impactos e problemas gerados pela Lei PRODEMI. Assim, para o SFDE de Itatiaia:

[...] houve aumento de procura por aluguéis e abertura de restaurantes (...). Um desafio é que não temos como fiscalizar a empresa por falta de pessoas qualificadas, com relação à contratação desses indicados (Trecho entrevista SFDE, 2016).

No que tange aos impactos gerados no município, fica nítida a evolução das receitas arrecadadas, as quais apresentaram salto considerável, no período de dezembro de 2009, de R\$ 50.293.052,55, para R\$ 125.190.009,66, de dezembro de 2015, conforme gráfico abaixo:

Gráfico 1. Receita Prefeitura Itatiaia (RJ) 2009 a 2016

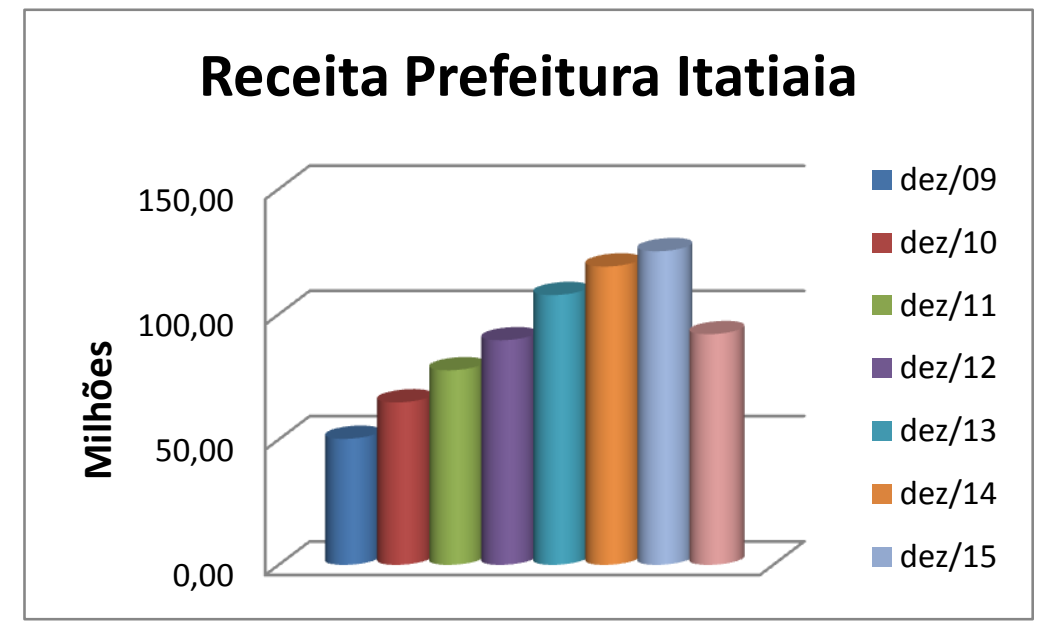

Fonte: Elaborado pelos autores.

Essa evolução pode ser associada, em partes, ao volume de investimentos atraídos para o município com a regulamentação da Lei PRODEMI a partir de junho de 2009, que abrangeu incentivos fiscais tanto a empresas interessadas em se instalar no município quanto para as já instaladas, desde que desenvolvessem projetos de expansão e/ou atividades que agregassem novos postos de trabalho (ITATIAIA, 2009). Tal fato motivou não só a atração de novos empreendimentos como fomentou a atividade tributária e as oportunidades de trabalho na realidade que já se observava no município. 
Desenvolvimento regional e lei PRODEMI: impactos sobre a geração de empregos e a receita pública em Itatiaia (RJ)

Além disso, o amplo alcance de empreendimentos contemplados pela lei, incluindo as atividades de varejo realizadas por meio de comércio eletrônico culminou em um maior número de empresas atendidas pelo benefício fiscal e o consequente acréscimo de receita. 0 art. $2^{\circ}$ da Lei Complementar $n^{0} 18$ de junho de 2009 diz que:

\footnotetext{
Poderão pleitear sua inclusão neste programa de incentivos todos os novos empreendimentos [...] voltados para as seguintes atividades empresariais:

I - Industriais

II - Operadoras logísticas e afins;

III - Comerciais atacadistas;

IV - Prestadoras de serviços;

V- Produtoras e distribuidoras de energia e gás;

VI - Condomínios e loteamentos;

VII - Comerciais varejistas que realizem vendas ao atacado e/ou varejo única e exclusivamente através de comércio eletrônico via Internet (ITATIAIA, 2009, p.l).
}

Em conformidade aos investimentos atraídos com a lei, na visão das empresas, a cidade de Itatiaia (RJ) se destaca devido à posição geográfica, assim como a infraestrutura dos modais de transportes existentes e boa topografia para instalação das empresas, gerando menor custo agregado e mão de obra de valor reduzido.

É possível observar, também, que houve ações legislativas por parte do Governo Federal que podem ser projetadas para o período supracitado em direção ao favorecimento da autonomia municipal, conforme estudo feito por Batista (2008) sobre matérias e leis nos governos FHC e Lula. Embora o escopo do levantamento do autor se limite ao primeiro mandato do presidente Luiz Inácio Lula da Silva (2003 - 2011), o mesmo se manteve no poder posteriormente, sendo seguido pelo governo de Dilma Rousseff até agosto de 2016 com a mesma dinâmica política, econômica e fiscal, o que pode ter favorecido, de certo modo, a receita do município.

Segundo Batista (2008), foram criadas a partir de 2003, 10 matérias legislativas favoráveis à autonomia municipal no que tange à área financeira, tributária e de gestão urbana (BATISTA, 2008, p.50).

Com relação aos empregos gerados, fica claro que houve uma disponibilidade considerada no período pós-aprovação da Lei PRODEMI. Entretanto, não se obteve êxito em saber se as vagas geradas pelas empresas beneficiam preferencialmente os moradores locais, visto que a SGER não possui dados suficientes e nem possui registros frequentes de retorno das empresas. De acordo com os dados mensurados do CAGED, foi possível verificar que foram 
gerados 10.892 admissões e 10.372 desligamentos, permanecendo assim um saldo positivo de 520 vagas de empregos.

\section{CONCLUSÃO}

Embora o objetivo do estudo fosse executar uma análise breve sobre o tema em questão, foi possível observar a existência de grande potencialidade do Programa de Desenvolvimento do Município de Itatiaia (PRODEMI). No entanto, há a necessidade de que os gestores públicos continuem estabelecendo metas baseadas no planejamento sustentável, na capacitação, no empreendedorismo e na fiscalização dos municípios, conforme o caráter emancipativo determinado na Constituição Federal de 1988, sobretudo em seu artigo 30, que determina as competências legislativas e materiais.

Salienta-se que o grande potencial do município de Itatiaia (RJ) se concentra por meio da sua localização privilegiada, incentivos fiscais, boa topografia e os modais existentes. Cabe ressaltar que ações inovadoras dos gestores podem garantir um desenvolvimento econômico sustentável; porém, como as principais empresas são de matrizes externas, configurando um desenvolvimento exógeno, existe a necessidade de planejamentos que visem um desenvolvimento endógeno, ou seja, aproveitar o que a região possui em prol do desenvolvimento, com o intuito de impactar diretamente na transformação da realidade local, além de contribuir para que a economia fique menos vulnerável às eventuais crises econômicas.

Neste sentido, o programa, com as devidas ressalvas, garante o desenvolvimento econômico sustentável, pois se verificou que houve um aumento das vagas de emprego. Para que os moradores locais se beneficiem dessas vagas de forma efetiva, há necessidade de ações do poder público com finalidade de promover a capacitação dos moradores, visto que as empresas estão exigindo candidatos cada vez mais qualificados e, no momento, não existe nenhum centro de capacitação no município, fazendo com que os moradores se desloquem para a cidade de Resende (RJ).

Não obstante, as dificuldades de acesso aos dados dos trabalhadores dificultaram uma parte do estudo, pois não existe um banco de dados na SGER, bem como o acesso aos setores 
Desenvolvimento regional e lei PRODEMI: impactos sobre a geração de empregos e a receita pública em Itatiaia (RJ)

de Recursos Humanos (RH) das empresas. Aqui cabe sugerir o planejamento pelos gestores públicos de um banco de dados que possam integrar os cadastros entre a empresa e o município, de forma que o processo permita a divulgação de dados mais fidedignos.

No tocante à capacitação da mão de obra local - e apesar de existir intenções na construção de um centro de capacitação - cabe ações que visam à construção desse centro, visto que já existe uma determinação na Lei PRODEMI para o recolhimento de 5\% do faturamento com finalidade de capacitação e qualificação profissional. Outra possibilidade que se mostra viável se faz presente em uma possível articulação intermunicipal entre os municípios de Itatiaia e Resende, na qual gestores poderiam buscar apoios mais contundentes nos centros de capacitação regionais que existem na cidade vizinha.

\section{REFERÊNCIAS BIBLIOGRÁFICAS}

BARQUER0, Antonio Vásquez. Desenvolvimento endógeno em tempos de globalização. Fundação de Economia e Estatística, 2002.

BATISTA, Matias Barboza. 0s municípios nos governos FHC e Lula: uma abordagem sob o ponto de vista da ação legislativa. $\quad$ Brasília, $2008 . \quad$ Disponível em: https://www2.senado.leg.br/bdsf/bitstream/handle/id/161444/Texto\%20Final.pdf?sequence=2>. Acesso em: 25 ago. 2017.

BRASIL. Constituição da República Federativa do Brasil de 1988. Disponível em: < http://www.planalto.gov.br/ccivil_03/constituicao/constituicaocompilado.htm>. Acesso em: 28 set. 2017.

CARVALH0, A. W. B. Associativismo municipal: resgate de uma estratégica para o planejamento em pequenos municípios. Anais... XII Encontro da Associação Nacional de Pós-Graduação e Pesquisa em Planejamento Urbano e Regional. 21 a 25 de maio de 2007. Belém - Pará - Brasil.

FERREIRA, A. Desenvolvimento regional: limites e possibilidades institucionais: um estudo de caso da região do Vale do Paraíba - RJ. Tese Doutorado em Políticas Públicas, Estratégias e Desenvolvimento. Universidade Federal do Rio de Janeiro. Instituto de Economia. 2012.

FERREIRA, A; LEOPOLDI, M. A; AMARAL, M. G. Desenvolvimento Regional: 0 Momento Atual e Perspectivas para a Região do Vale do Paraíba Fluminense. Anais... I Seminário de Desenvolvimento Regional, Estado e Sociedade. Rio de Janeiro. 2012.

FERREIRA, A. Poder público local, universidades e desenvolvimento regional: uma análise da Região do Médio Paraíba Fluminense. Revista Brasileira de Gestão e Desenvolvimento Regional. GËDR. v. 10, n. 1, p. 305-359, janabr/2014, Taubaté, SP, Brasil.

GERHARDT, Tatiana Engel; SILVEIRA, Denise Tolfo (Org.). Métodos de pesquisa. UFRGS, 2009. Disponível em:

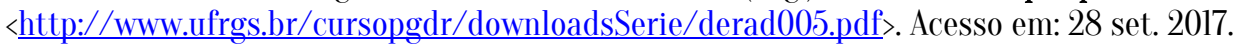

GOLDENBERG, Mirian. A arte de pesquisar. Rio de Janeiro: Silverio, 1997. 
HELCIAS, Elisangela Maria da Silva. A estrutura federativa dos municípios na perspectiva da Constituição Federal de 1988. Jus. 2015. Disponível em: < https://jus.com.br/artigos/50844/a-estrutura-federativa-dos-municipios-naperspectiva-da-constituica0-federal-de-1988>. Acesso em: 25 ago. 2017.

IBGE. Instituto Brasileiro de Geografia e Estatística. Histórico. Disponível em: 〈http://cod.ibge.gov.br/2W352〉. Acesso em: 12 set. 2016.

ITATIAIA. Decreto N. 1.810 de 8 de dezembro de 2009. Regulamenta a Lei Complementar n. 18/2009, de 10 de junho de 2009. Disponível em: 〈http://itatiaia.rj.gov.br/secretaria/108/desenv-economico〉. Acesso em: 12 set. 2016.

. Lei Complementar $n^{0}$ 18, de 10 de junho de 2009. Institui e regulamenta o Programa de Desenvolvimento Econômico do Município de Itatiaia - PRODEMI e dá outras providências. Disponível em: < http://itatiaia.rj.gov.br/downloads/36/lei-complementar-18-de-2009--prodemi>. Acesso em: 29 ago. 2017.

LIMA, Ana Carolina da Cruz; SIMÕES, Rodrigo Ferreira. Teorias do desenvolvimento regional e suas implicações de política econômica no Pós-Guerra: 0 caso do Brasil. UFMG, 2009. Disponível em: < http://www.cedeplar.ufmg.br/pesquisas/td/TD\%20358.pdf>. Acesso em: 28 set. 2017.

MARIANO, F. C. DE SOUZA, A. C. B. DA SILVA, J. L. G. da Silva, MEIRELLES, E. G. e JUNIOR, D. M. P. Transporte de cargas: uma análise sobre os modais e sua aplicação na região Sul Fluminense. Revista ADM Gestão Estratégica, Ponta Grossa, v. 6, n. 1, p.37-45, 2013.

MTE. Ministério do Trabalho e Emprego. Proger - Base de Gestão. Disponível em: < http://bi.mte.gov.br/cagedestabelecimento/pages/resultado.xhtml>. Acesso em: 05 out. 2016. 